\title{
Prevention of Maternal-to-Child Transmission of HIV: Knowledge, Attitude and Factors Influencing Active Participation among HIV-Positive Men in a Military Health Facility in Lagos, South Western Nigeria
}

\author{
Nkechinyere Elizabeth Harrison 1,2*, Kenneth Ejiofor Oruka1, Uzoamaka Concilia Agbaim1, \\ Olatunde Ademola Adegbite ${ }^{1}$, Obiyo Nwaiwu ${ }^{3}$, Nathan Anelechi Elvis Okeji ${ }^{4}$ \\ ${ }^{1}$ Centre for Infectious Disease Clinic, 68 Nigerian Army Reference Hospital Yaba, Lagos, Nigeria \\ ${ }^{2}$ Department of Medicine, 68 Nigerian Army Reference Hospital Yaba, Lagos, Nigeria \\ ${ }^{3}$ Department of Pharmacology, Therapeutics and Toxicology, Faculty of Basic Medical Sciences, College of Medicine, \\ University of Lagos, Lagos, Nigeria \\ ${ }^{4}$ Ministry of Defence, Health Implementation Programme, Abuja, Nigeria \\ Email: *nke1207@yahoo.com
}

How to cite this paper: Harrison, N.E., Oruka, K.E., Agbaim, U.C., Adegbite, O.A., Nwaiwu, O. and Okeji, N.A.E. (2020) Prevention of Maternal-to-Child Transmission of HIV: Knowledge, Attitude and Factors Influencing Active Participation among HIVPositive Men in a Military Health Facility in Lagos, South Western Nigeria. Open Journal of Preventive Medicine, 10, 233-253. https://doi.org/10.4236/ojpm.2020.108017

Received: August 3, 2020

Accepted: August 21, 2020

Published: August 24, 2020

Copyright $\odot 2020$ by author(s) and Scientific Research Publishing Inc. This work is licensed under the Creative Commons Attribution International License (CC BY 4.0).

http://creativecommons.org/licenses/by/4.0/ (c) (i) Open Access

\begin{abstract}
Introduction: Traditionally, Prevention of Maternal-to-Child Transmission (PMTCT) of HIV involves women and excludes men despite their important roles. There is a need for more data on factors influencing male participation in PMTCT programs. Design: This was a cross-sectional, descriptive study of married HIV-positive men receiving care at the adult ART clinic, 68 Nigerian Army Reference Hospital Yaba. Data were collected from March 15 to April 30, 2018. Result: Out of the 366 respondents, 333 (91\%) were aware that HIV can be transmitted from mother to child. However, only $43.2 \%$ correctly identified that it can be transmitted during pregnancy, while $30.2 \%$ stated during labour. Almost all of the respondents (96.4\%) would also accept that their positive partners take antiretroviral treatment to protect her unborn baby, $86.9 \%$ would support non breastfeeding option after delivery, and $95.6 \%$ indicated readiness to buy formula milk for the baby. Similarly, majority believed that a pregnant woman can be tested for HIV without the permission of her partner (Mean $=1.47 \pm 0.893$ ), and that men should accompany their spouse to ANC/PMTCT clinics (Mean $=1.86 \pm 0.921$ ). Conclusion: This study revealed that despite low knowledge of PMTCT among men, there is a good level of attitude and involvement among them. We recommend further study to fully explore the impact of education on men's participation.
\end{abstract}




\section{Keywords}

Prevention, Maternal to Child, HIV Transmission, Men, Attitude, Practice, Nigeria

\section{Introduction}

Globally, Maternal-to-Child Transmission (MTCT) accounts for 90\% of HIV infections in children under the age of 15 years [1]. In sub-Saharan Africa (SSA), prevalence of HIV is reportedly high (59\%) among women, and may not be unconnected to the high transmission rate among children [2]. In 2013 alone, an estimated 240,000 new pediatric infection occurred, which is equivalent to 1 child being infected every 2 minutes [3]. Fondoh and Mom equally reported that out of the estimated four million children living with HIV in 2016, 90\% were resident in SSA [1].

In Nigeria, the burden of MTCT is exemplified by her fair share of $90 \%$ of pregnant women living with HIV among the 22 countries worst hit by this epidemic [4]. In the year 2010, only $16.9 \%$ of pregnant women in Nigeria were tested for HIV, which may have contributed to an estimated 75,000 HIV-infected infants in the same year [5] [6] [7]. In the following year, the Nigeria National Agency for the Control of AIDS also reports that about 1.72 million women and girls were still living with HIV/AIDS despite heightened intervention to reverse the trend [8]. Although there was little improvement recorded in 2012, an estimated 60,000 new HIV infection still occurred among children, thereby ranking Nigeria first among the countries with highest number of children infected through MTCT [9]. Additionally, Iwelumnor et al. also observed that Nigeria alone accounts for $30 \%$ of the global burden of MTCT of HIV [4]. These figures are startling, and highlight the important of scaling up the current efforts at containing pediatric HIV infection.

Since MTCT is the main means of child transmission, recent global efforts have centered on the virtual elimination of pediatric HIV through Prevention of Mother-to-Child Transmission (PMTCT) programs [10]. The importance of these programs has been shown by their ability to help prevent more than 800,000 children from becoming newly infected between 2005 and the end of 2012 [11]. Takah, and colleague also report that between 2009 and 2012, interventions directed towards the improvement of PMTCT services resulted in the curtailing HIV in about 670,000 children in SSA [12]. These facts have been corroborated by UNAIDS report which noted that PMTCT programs can substantially reduce the risk of vertical HIV transmission from greater than $40 \%$ to less than 5\% [3].

Nevertheless, evidence shows that without involvement of male partners, uptake and strict adherence to these PMTCT have been challenging for some women [13]. Effectiveness of PMTCT efforts depend on an interwoven family's decision-making dynamics which is championed by men, due to the pivotal role they 
play in the family. Shared decision-making have been shown to facilitate participation in health care programs including PMTCT, especially in SSA where reproductive health decisions are greatly influenced by male partners [14] [15] [16]. But in reality, traditional PMTCT is focused mainly on women, thereby disregarding important roles played by men and may be responsible for the little impact made so far [17].

Exploration of the different ways in which PMTCT programs could be supported in order to improve outcomes especially in Nigeria is therefore imperative. There is ample evidence documenting the positive contributions men can make in the successful implementation of sexual and reproductive health programs in Africa and PMTCT of HIV in particular [18] [19] [20]. As such, male partner involvement in PMTCT programs has been promoted as one of the priority interventions to improve its outcomes in sub-Saharan African countries [21]. This is because men's constructive involvement in the programs has resulted in positive health outcomes for women, children and families, and is not unconnected with the social power men hold in patriarchal settings [22] [23]. However, inadequate partner support and men's limited knowledge and attitude about the interconnection between antenatal care and prevention of HIV, for example, often act as a hindrance to seeking early and effective care. The World Health Organization reports that many countries focus sexual and reproductive health programs and services around women, making men to often lack information that could help their informed decision making regarding the requisite roles they could play to promote overall family health, including accessing HIV prevention, care and treatment services [20].

Additionally, there is a dearth of information regarding factors influencing participation in PMTCT programs among men living with HIV. The existing literature on the role of men in sexual and reproductive health has also paid little attention to the roles of HIV-infected persons. Therefore, assessment of level of knowledge, attitude/level of involvement and perceived factors influencing male involvement in PMTCT of HIV among HIV-positive men will provide enabling tool to further tailor strategies for social behavioural change, through teaching/counselling in order to enhance effective implementation of PMTCT programs. Therefore, this study aims to assess the knowledge, attitude and practice of HIV positive men towards PMTCT in an Army Hospital in Lagos.

\section{Methods}

\subsection{Study Design}

This was cross-sectional study which employed quantitative, non-experimental descriptive survey method.

\subsection{Study Site}

The study was conducted at 68 Nigerian Army Reference Hospital Yaba (68NARHY), Lagos. 68NARHY is a 500 bed capacity tertiary military hospital 
which serves about 6000 in-and-out patients per month provides referral services to the Nigerian service men and civilians alike. This is located in Yaba Local Council Development Area of Lagos State. The area lies in south western Nigeria, in the Gulf of Guinea, west of the Niger River delta. It is located on the longitude $3^{\circ} 24^{\prime} \mathrm{E}$ and latitude $6^{\circ} 27^{\prime} \mathrm{N}$. The monthly rainfall varies from the lowest of $35 \mathrm{~mm}$ (1.5 inches) in January to the highest of $300 \mathrm{~mm}$ (12 inches) in July. It runs daily adult HIV clinic at its Centre for Infectious Disease Clinic (CID) with average daily clinic attendance of 100 clients.

\subsection{Study Population}

The population for the study was all married HIV-positive men receiving care at the adult ART clinic, 68 Nigerian Army Reference Hospital Yaba, who provided oral informed consent to participate in the study.

\subsection{Sample Size Estimation}

The sample size of 384 participants was determined using the formula for calculating sample size for descriptive survey proposed by Chrane (1963) as follows:

$$
n=\frac{z^{2} p q}{e^{2}} \quad \text { Cochrane 1963: 75) }
$$

where:

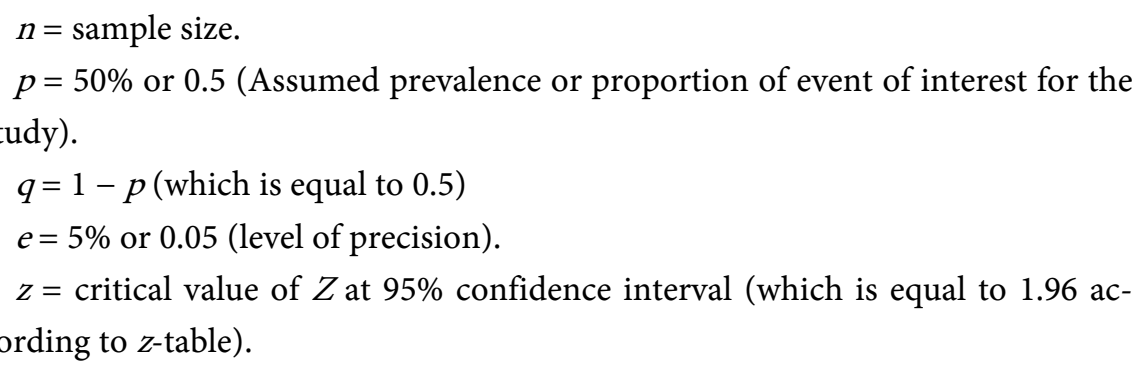

\subsection{Data Collection}

Four research assistants were trained by the lead researcher on the questionnaire, data collection procedures and sampling methods. A pre-tested structured questionnaire $(r=0.763)$ was used to obtain information on the participants' socio-demographic characteristics, HIV/AIDS and PMTCT-related knowledge, attitude/level of involvement, and factors influencing male participation in PMTCT services. The questionnaire was adapted with modifications from already published works [1] [16] [21]. Purposive sampling method was used to select every married adult male participant (aged 18 years and above) who consented to take part in the study until a total number of 380 questionnaires were distributed, at which no other indicated interest. The questionnaires were self-administered but the respondents were supervised by the research assistants while they filled them in order to ensure accuracy and consistency of responses. The distribution and collection of questionnaires lasted for six weeks, from March 15 to April 30, 2018. 


\subsection{Data Analysis}

Statistical Package for Social Sciences (SPSS version 23.0, IBM, Armonk, NY, USA) was used to analyze the data after cleaning, coding, and entry. The primary outcomes of the study were knowledge of PMTCT services as defined by being up to date with the concept of HIV/AIDS and PMTCT services; attitude/ level of involvement as defined by willingness to support and active participation in PMTCT services; and factors influencing effective delivery of PMTCT services as identified by the participants. All correct responses in the relevant sections were scored as 1 while incorrect and "don't know" responses were scored as 0 . The scores were summed to form two indexes: HIV/PMTCT knowledge (score range 0 - 28; Cronbach's alpha $=0.846$ ), and Attitude/involvement in PMTCT (score range 0 - 10; Cronbach's alpha $=0.756$ ). Sum of scores were categorized as low knowledge (score $<20$ points) or high knowledge (score $\geq 20$ points); and poor attitude/involvement (score $<7$ points) or good attitude/involvement (Score $\geq 7$ points). Descriptive statistics (mean and standard deviation) was used to analyze the scale items. The items were scored such that "strongly agreed" was scored as 1 point, and other intermediate responses scored in increasing order until "strongly disagreed" which was scored as 5 point. Reverse interpretations were applied to the respective items where necessary. The distribution of each selected socio-economical variable was compared between those who demonstrated good knowledge of PMTCT services and those who did not using chi square (Fisher's exact test). In all analyses, a $p$-value of $\leq 0.05$ was considered statistically significant.

\subsection{Ethical Considerations}

Prior to study onset, approval was obtained from the 68 Nigerian Army Reference Hospital Yaba, (68NARHY) Research Ethics Committee. Opportunities were given for the participants to ask questions, after which oral informed consent was obtained from each participant before administration of the questionnaire. To ensure confidentiality, the questionnaire was anonymized and after data collection, all were stored in a safe that was accessible only to the lead researcher.

\section{Result}

Of the 380 questionnaires distributed for the study, 366 representing $96 \%$ were retrieved and included in this analysis. Findings showed that majority $(74.8 \%)$ of the interviewees were aged between 35 and 54 years (Mean $44.88 \pm 8.76$ ), over half (57.7\%) were school certificate holders, while greater than two-third (78.4\%) have lived with their partners for more than 5 years. Most of the respondents (78.7\%) were Christians by religious believe, but were distributed across three major ethnic groups in Nigeria with Igbos (38\%) topping in the list, after Yoruba $(29.5 \%)$. In addition, greater proportion of the respondents were engaged in one work or the other [84.2\%]. Table 1 shows the respondents' economic and de- 
mographic characteristics of study participants.

Result further showed that respondents received their information about HIV/ AIDS from various sources and in most cases from a multiple source. Hospital (46.2\%) topped in the chart, followed by social gathering (23.2\%), Television (19.7\%) and Radio (18.0\%) among others (Figure 1).

Out of the 366 respondents, 333 (91\%) were aware that HIV can be transmitted from mother to child. However, only $43.2 \%$ correctly identified that it can be transmitted during pregnancy, while $30.2 \%$ stated during labour. Regarding factors which could encourage MTCT of HIV, baby's mother being sick, development of cracked nipples or prematurity of the baby were identified as risk factors by only $28.2 \%, 47.4 \%$ and $9.9 \%$ respectively (Table 2 ).

In summary, there was an overall reported low level of knowledge about HIV/PMTCT among the respondents (Figure 2), with school cert holders (Phi=

Table 1. Showing the respondents' economic and demographic characteristics.

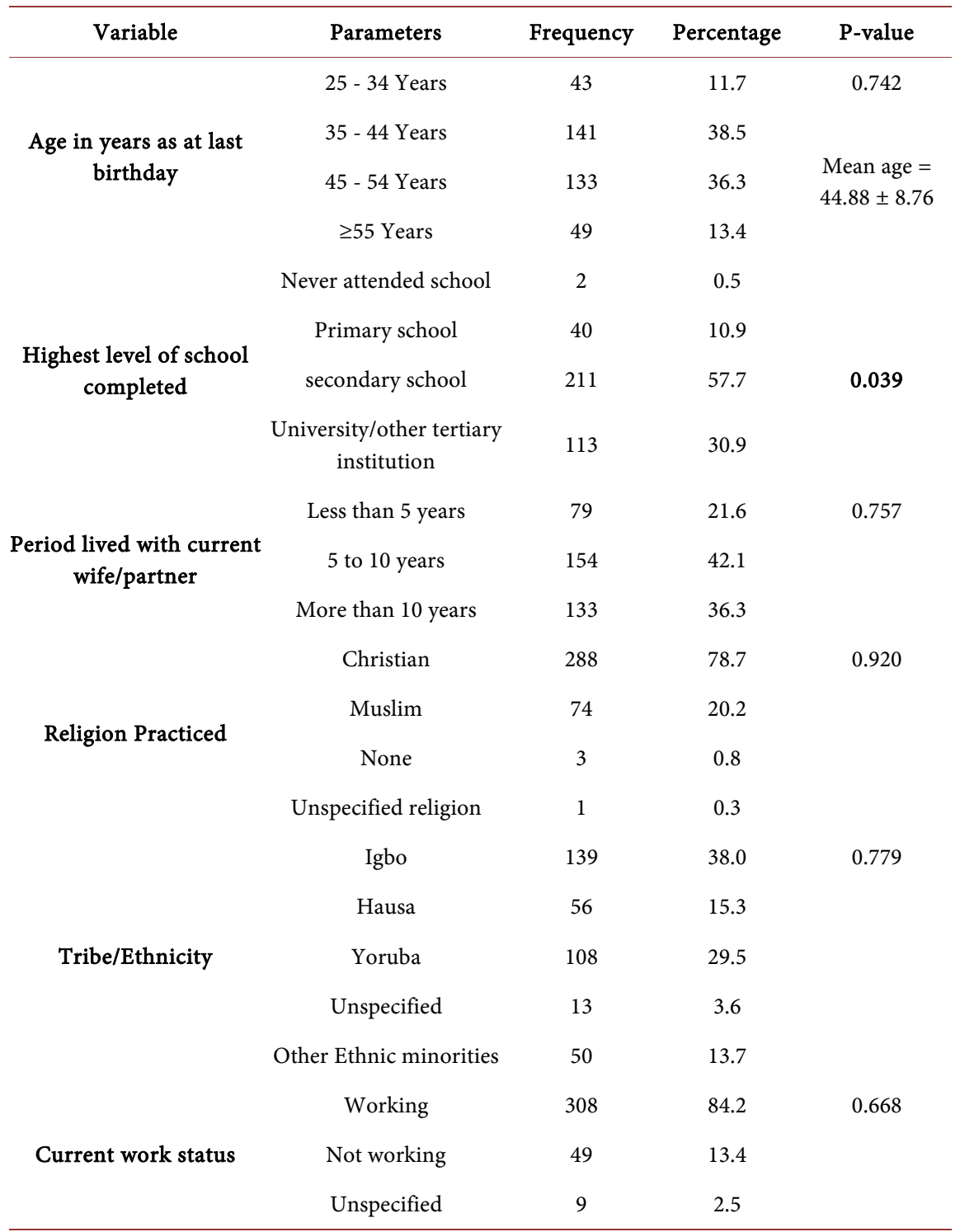


Table 2. Showing respondents knowledge and awareness of PMTCT.

\begin{tabular}{|c|c|c|c|c|}
\hline \multirow{2}{*}{ Assessment Questions } & \multirow[b]{2}{*}{ Variables } & \multicolumn{3}{|c|}{ Responses } \\
\hline & & $\begin{array}{c}\text { Yes } \\
\mathrm{n}(\%)\end{array}$ & $\begin{array}{c}\text { No } \\
\mathrm{n}(\%)\end{array}$ & $\begin{array}{l}\text { I don't know } \\
\text { n (\%) }\end{array}$ \\
\hline \multicolumn{2}{|c|}{ Can HIV be transmitted from mother to child? $\mathrm{N}=366$} & $333(91.0)$ & $12(3.3)$ & $21(5.7)$ \\
\hline \multirow{4}{*}{$\begin{array}{l}\text { If yes to the question above when? } \\
\mathrm{N}=333\end{array}$} & During pregnancy & $144(43.2)$ & $87(26.1)$ & $102(30.6)$ \\
\hline & During labour & $102(30.2)$ & $127(38.1)$ & $104(31.2)$ \\
\hline & During delivery & $204(61.3)$ & $65(19.5)$ & $64(19.2)$ \\
\hline & During breastfeeding & $305(91.6)$ & $11(3.3)$ & $17(5.1)$ \\
\hline \multirow{7}{*}{$\begin{array}{l}\text { What do you think will encourage } \\
\text { transmission of HIV from mother } \\
\text { to child? } \\
\mathrm{N}=333\end{array}$} & Increased mother's viral load & $287(86.2)$ & $20(6.0)$ & $26(7.8)$ \\
\hline & Lack of multivitamins & $67(20.1)$ & $134(40.2)$ & $132(39.6)$ \\
\hline & When mother is sick & $94(28.2)$ & $118(35.4)$ & $121(36.3)$ \\
\hline & Mother having cracked nipples & $158(47.4)$ & $64(19.2)$ & $111(33.3)$ \\
\hline & Premature baby & $33(9.9)$ & $245(73.6)$ & $55(16.5)$ \\
\hline & Hugging the baby & $12(3.6)$ & $292(87.7)$ & $29(8.7)$ \\
\hline & Sharing same bed with baby & $11(3.3)$ & $292(87.7)$ & $30(9.0)$ \\
\hline \multirow{8}{*}{$\begin{array}{l}\text { Mother to child transmission of } \\
\text { HIV can be prevented by? } \\
\mathrm{N}=333\end{array}$} & Pregnant women eating balance diet & $96(28.8)$ & $83(24.9)$ & $154(46.2)$ \\
\hline & Caesarian section before the onset of labour & $129(38.7)$ & $55(16.5)$ & $149(44.7)$ \\
\hline & $\begin{array}{l}\text { Giving of antiretroviral drugs to mother during and after } \\
\text { pregnancy. }\end{array}$ & $294(88.3)$ & $16(4.8)$ & $23(6.9)$ \\
\hline & Use of breast milk substitute (powdered milk). & $234(70.3)$ & $48(14.4)$ & $51(15.3)$ \\
\hline & Avoiding breast milk. & $251(75.4)$ & $45(13.5)$ & $37(11.1)$ \\
\hline & Use of directly expressed and boiled mother's breast milk. & $38(11.4)$ & $183(55.0)$ & $112(33.6)$ \\
\hline & Breastfeeding baby by another mother who is not HIV infected. & $67(20.1)$ & $153(45.9)$ & $113(33.9)$ \\
\hline & Attend antenatal clinic regularly. & $341(93.2)$ & $5(1.4)$ & $20(5.5)$ \\
\hline \multirow{3}{*}{$\begin{array}{l}\text { Are you aware that HIV infected } \\
\text { pregnant woman should? } \\
\mathrm{N}=366\end{array}$} & Be delivered by a skilled attendant (doctor or a midwife). & $328(89.6)$ & $11(3.0)$ & $27(7.4)$ \\
\hline & Visit post-natal clinic 6 weeks after delivery. & $319(87.2)$ & $15(4.1)$ & $32(8.7)$ \\
\hline & Visit family planning clinic 6 weeks after delivery. & $284(77.6)$ & $24(6.6)$ & $58(15.8)$ \\
\hline \multicolumn{2}{|c|}{$\begin{array}{l}\text { Have you ever heard about a programme called prevention of mother to child transmission } \\
(\text { PMTCT)? } \mathrm{N}=366\end{array}$} & $279(76.2)$ & $36(9.8)$ & $51(13.9)$ \\
\hline \multicolumn{2}{|c|}{ Are PMTCT services offered at this hospital? N $=366$} & $238(65.0)$ & $16(4.4)$ & $112(30.6)$ \\
\hline \multicolumn{2}{|c|}{ At the PMTCT clinics, are pregnant women counseled and tested for HIV? $\mathrm{N}=366$} & $259(70.8)$ & $5(1.4)$ & $102(27.9)$ \\
\hline \multicolumn{2}{|c|}{ Was your wife or partner tested for HIV when she was last pregnant? $\mathrm{N}=366$} & $280(76.5)$ & $51(13.9)$ & $35(9.6)$ \\
\hline
\end{tabular}

$0.149)$ demonstrating a statistically significant higher knowledge, $\chi^{2}(3)=7.6,(p$ $=0.039$ ).

Table 3 revealed that 280 (76.5\%) of the total respondents interviewed knew that their partners were counseled and tested for HIV in the last pregnancy, 252 (68.5) discussed this with their partner and yet another 337 (92.1\%) expressed willingness to discuss this the next time their partner will be pregnant. Almost 


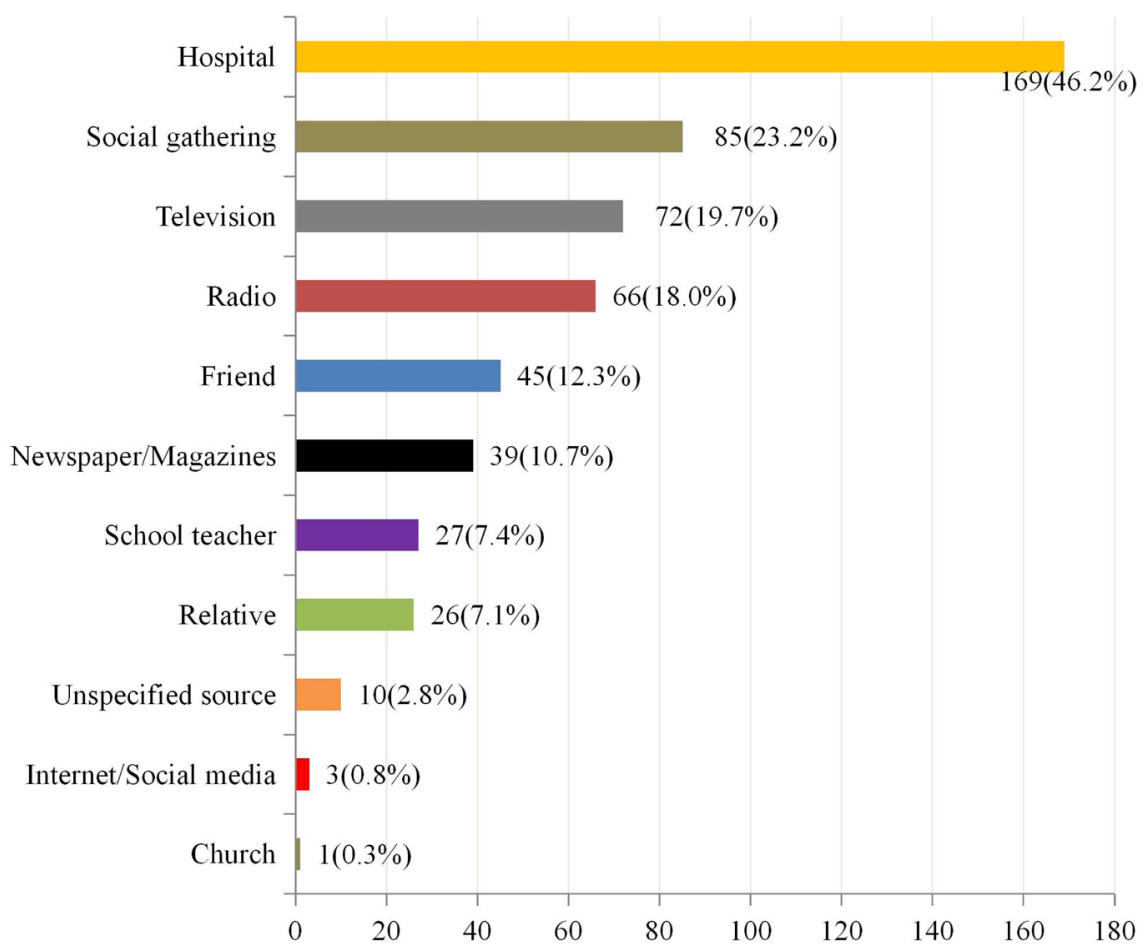

Figure 1. Bar diagram showing respondents sources of information about HIV/AIDS, N $=366$.

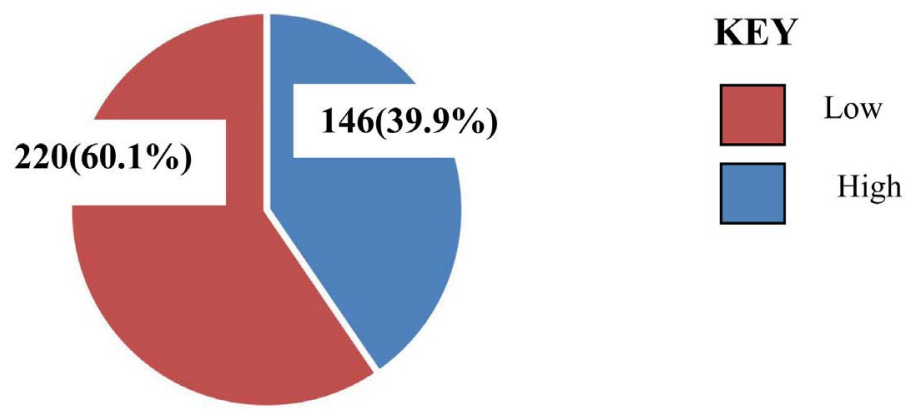

Figure 2. Pie chart showing the overall level of awareness of PMTCT among the respondents.

Table 3. Showing the attitude/male involvement in PMCTC. $\mathrm{N}=366$.

\begin{tabular}{|c|c|c|c|}
\hline \multirow[b]{2}{*}{ Assessment Variables } & \multicolumn{3}{|c|}{ Responses } \\
\hline & $\begin{array}{c}\text { Yes } \\
\text { n (\%) }\end{array}$ & $\begin{array}{c}\text { No } \\
\mathrm{n}(\%)\end{array}$ & $\begin{array}{l}\text { I don't know } \\
\text { n (\%) }\end{array}$ \\
\hline $\begin{array}{l}\text { Was your wife/partner counseled and tested for HIV the last } \\
\text { time she was pregnant? }\end{array}$ & $280(76.5)$ & $49(13.4)$ & $37(10.1)$ \\
\hline $\begin{array}{l}\text { Did you discussed with your wife/partner about counseling } \\
\text { and testing for HIV last time she was pregnant? }\end{array}$ & $252(68.5)$ & $78(21.3)$ & $36(9.8)$ \\
\hline $\begin{array}{l}\text { Will you discuss with your wife/partner about counseling } \\
\text { and testing for HIV next time she is pregnant? }\end{array}$ & $337(92.1)$ & $14(3.8)$ & $15(4.1)$ \\
\hline $\begin{array}{l}\text { Have you ever gone together with your/partner to an } \\
\text { MCH/PMTCT clinic? }\end{array}$ & $225(61.5)$ & $110(30.1)$ & $31(8.5)$ \\
\hline
\end{tabular}




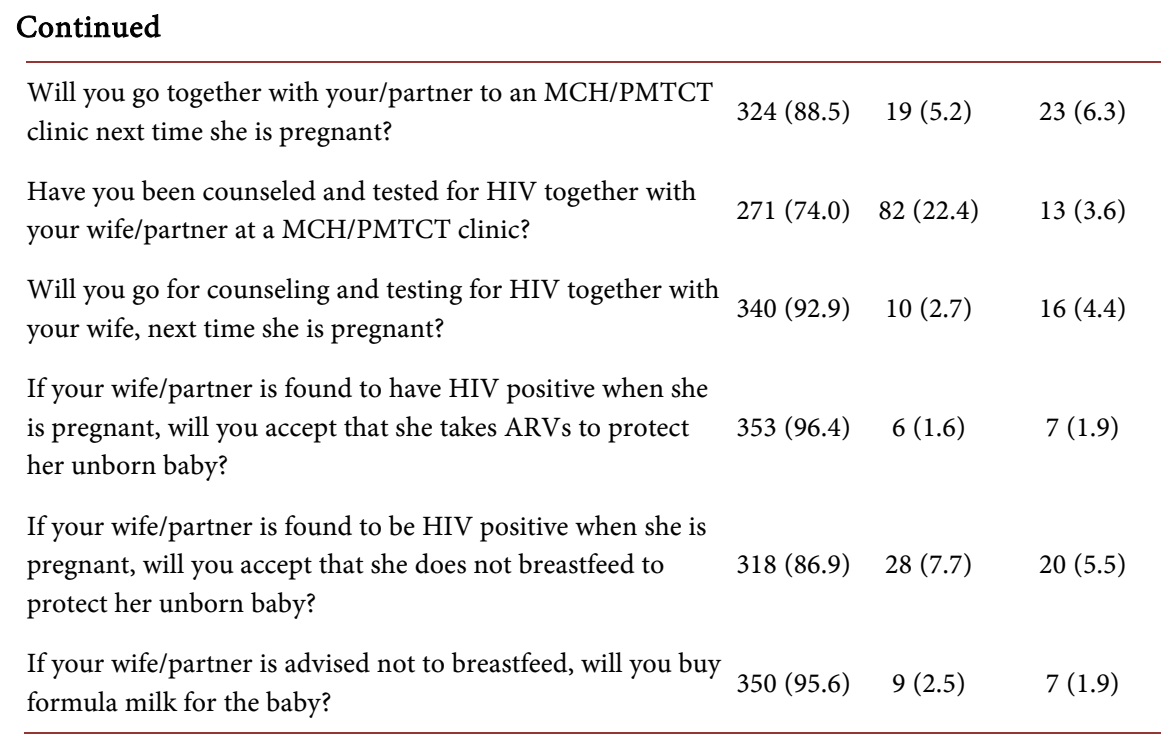

all of the interviewees (96.4\%) would also accept that their positive partners take antiretroviral treatment to protect her unborn baby, $86.9 \%$ would support non breastfeeding option after delivery, and $95.6 \%$ indicated readiness to buy formula milk for the baby.

Overall, the reported attitude/involvement in PMTCT among the respondents was $83.9 \%$ (Figure 3 ).

Regarding the respondents' perceived socio cultural factors influencing male participation in PMTCT programs, Table 4 shows that over half of the respondents (50.8\%) were undecided about whether PMTCT information should first be given to men before women (Mean $=3.15 \pm 1.058$ ). However, majority believed that a pregnant woman can be tested for HIV without the permission of her husband/partner $($ Mean $=1.47 \pm 0.893)$, that men should accompany their spouse to ANC/PMTCT clinics (Mean $=1.86 \pm 0.921$ ), declined to a myth labeling men who accompany their female partners to ANC/PMTCT clinics as weak or being bewitched (Mean $=4.01 \pm 1.085$ ), as well as insinuation that ANC/PMTCT clinics are for women and children only (Mean $=2.62 \pm 1.190$ ); etc.

According to Table 5, 39.1\% of the respondents were in concord that PMTCT/ Adult ART clinics should also be opened during weekends and evening so that men can access (Mean $=2.72 \pm 1.119$ ), although up to $38 \%$ of the subjects were indecisive regarding such weekend clinics. Moreover, about half believed that PMTCT programs have done very little to involve men $($ Mean $=2.93 \pm 1.171)$, and that they can attend PMTCT clinics if invited by health workers to come $($ Mean $=2.52 \pm 1.16)$; etc.

\section{Discussion}

Our study revealed that the overall knowledge of PMTCT among the respondents was poor (39.9\%). Although significant proportion of the respondents knew that HIV can be transmitted from mother to child, they had poor knowledge of the transmission routes, means, risk factors for such transmission, as 
Table 4. Showing socio cultural factors. $\mathrm{N}=366$.

\begin{tabular}{|c|c|c|c|c|c|c|c|}
\hline & \multicolumn{7}{|c|}{ Responses } \\
\hline & $\begin{array}{l}\text { Strongly } \\
\text { Agreed }\end{array}$ & Agreed & $\begin{array}{c}\text { Un } \\
\text { Decided }\end{array}$ & Disagreed & $\begin{array}{l}\text { Strongly } \\
\text { Disagreed }\end{array}$ & & \\
\hline Variables & n (\%) & n (\%) & n (\%) & n (\%) & n (\%) & Mean & $\pm \mathrm{SD}$ \\
\hline $\begin{array}{l}\text {-A pregnant woman can be tested for HIV without the } \\
\text { permission of her husband/partner. }\end{array}$ & $256(69.9)$ & $77(21.0)$ & $13(3.6)$ & $11(3.0)$ & $9(2.5)$ & 1.47 & 0.893 \\
\hline $\begin{array}{l}\text {-Men should accompany their pregnant wives/partners to } \\
\text { ANC/PMTCT clinics. }\end{array}$ & $149(40.7)$ & $150(41.0)$ & $40(10.9)$ & $23(6.3)$ & $4(1.1)$ & 1.86 & 0.921 \\
\hline $\begin{array}{l}\text {-Men who accompany their female partners to ANC/PMTCT } \\
\text { clinics are weak or bewitched. }\end{array}$ & $21(5.7)$ & $17(4.6)$ & $36(9.8)$ & $155(42.3)$ & $137(37.4)$ & 4.01 & 1.085 \\
\hline $\begin{array}{l}\text {-It is a taboo for men to discuss with women about HIV testing } \\
\text { during pregnancy. }\end{array}$ & $36(9.8)$ & $13(3.6)$ & $25(6.8)$ & $116(31.7)$ & $176(48.1)$ & 4.05 & 1.256 \\
\hline $\begin{array}{l}\text {-Men and women should undergo HIV testing at the same time at } \\
\text { PMTCT clinics. }\end{array}$ & $106(29.0)$ & $131(35.8)$ & $110(30.1)$ & $17(4.6)$ & $2(0.2)$ & 2.12 & 0.902 \\
\hline $\begin{array}{l}\text {-Couples can use condoms to reduce chances of mother to child } \\
\text { transmission of HIV. }\end{array}$ & $113(30.9)$ & $167(45.6)$ & $64(17.5)$ & $11(3.0)$ & $11(3.0)$ & 2.02 & 0.936 \\
\hline -ANC/PMTCT clinics are for women and children only. & $48(13.1)$ & $168(45.9)$ & $69(18.9)$ & $38(10.4)$ & $43(11.7)$ & 2.62 & 1.190 \\
\hline $\begin{array}{l}\text {-A positive HIV test in a pregnant woman shows that she has } \\
\text { been unfaithful to her husband. }\end{array}$ & $17(4.6)$ & $11(3.0)$ & $40(10.9)$ & $121(33.1)$ & $177(48.4)$ & 4.17 & 1.051 \\
\hline $\begin{array}{l}\text {-If a pregnant woman is found to be HIV positive, she should be } \\
\text { divorced. }\end{array}$ & $10(2.7)$ & $3(0.8)$ & $34(9.3)$ & $111(30.3)$ & $208(56.8)$ & 4.38 & 0.894 \\
\hline -PMTCT information should first be given to men than women. & $33(9.0)$ & $36(9.8)$ & $186(50.8)$ & $65(17.8)$ & $46(12.6)$ & 3.15 & 1.058 \\
\hline
\end{tabular}

$\mathrm{SD}=$ Standard deviation

Table 5. Showing programmatic factors. $\mathrm{N}=366$.

\begin{tabular}{|c|c|c|c|c|c|c|c|}
\hline & \multicolumn{7}{|c|}{ Responses } \\
\hline & $\begin{array}{l}\text { Strongly } \\
\text { Agreed }\end{array}$ & Agreed & $\begin{array}{l}\text { Un } \\
\text { Decided }\end{array}$ & Disagreed & $\begin{array}{l}\text { Strongly } \\
\text { Disagreed }\end{array}$ & & \\
\hline Variables & $\mathrm{n}(\%)$ & n (\%) & n (\%) & n (\%) & n (\%) & Mean & $\pm \mathrm{SD}$ \\
\hline -Men should have "male only PMTCT clinics". & $48(13.1)$ & $73(19.9)$ & $130(35.5)$ & $66(18.0)$ & $49(13.4)$ & 2.99 & 1.202 \\
\hline -Health workers do not like to see men at PMTCT clinics & $16(4.4)$ & $44(12.0)$ & $119(32.5)$ & $119(32.5)$ & $68(18.6)$ & 3.49 & 1.062 \\
\hline -MCH/PMTCT clinics are made for women and children. & $29(7.9)$ & $111(30.3)$ & $96(26.2)$ & $87(23.8)$ & $43(11.7)$ & 3.01 & 1.154 \\
\hline $\begin{array}{l}\text {-PMTCT/Adult ART clinics should also be opened during } \\
\text { weekends and evening so that men can access also }\end{array}$ & $68(17.5)$ & $79(21.6)$ & $139(38.0)$ & $62(16.9)$ & $22(6.0)$ & 2.72 & 1.119 \\
\hline -PMTCT programmes have done very little to involve men. & $36(9.8)$ & $111(30.3)$ & $104(28.4)$ & $71(19.4)$ & $44(12.0)$ & 2.93 & 1.171 \\
\hline $\begin{array}{l}\text {-You can attend PMTCT clinics if invited by health workers } \\
\text { to come. }\end{array}$ & $75(20.5)$ & $130(35.5)$ & $78(21.3)$ & $62(16.9)$ & $21(5.7)$ & 2.52 & 1.160 \\
\hline $\begin{array}{l}\text {-PMTCT clinics are conducted very far from your home and } \\
\text { transport is expensive. }\end{array}$ & $50(13.7)$ & $72(19.7)$ & $106(29.0)$ & $105(28.7)$ & $33(9.0)$ & 3.00 & 1.181 \\
\hline $\begin{array}{l}\text {-You can do HIV test with your wife, only if you are promised } \\
\text { to be given ARVs thereafter. }\end{array}$ & $57(15.6)$ & $55(15.0)$ & $113(30.9)$ & $90(24.6)$ & $51(13.9)$ & 3.06 & 1.256 \\
\hline
\end{tabular}

$\mathrm{SD}=$ Standard deviation. 


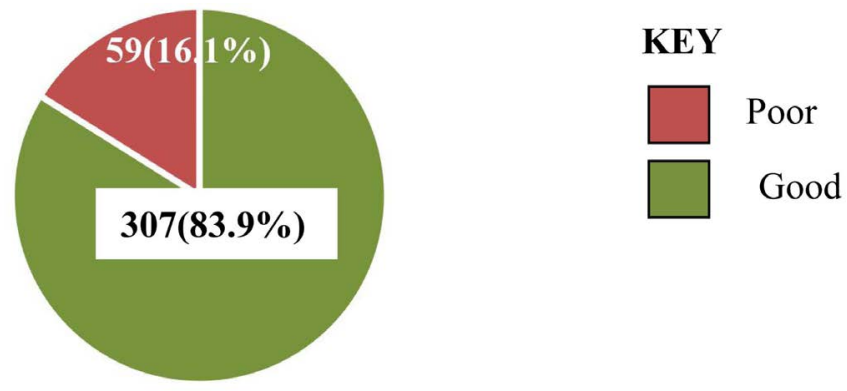

Figure 3. Pie chart showing the overall attitudes and extent of involvement in PMTCT.

well preventive measures. Our result is in disagreement with a South African study [23] which showed that men demonstrated overall good knowledge about PMTCT and the potential roles they could play in the program. Although our study employed structured interview of male partners only, while the former was a focused group discussion among male partners, and in turn their female partners who reported their perception of the roles of their male partners in PMTCT. However, this finding agrees with the observations in two other studies [24] [25] which noted that men had generally limited knowledge on PMTCT, stating that they neither understood what it meant nor of what importance it was. This has great implication on the overall success of the program; partners who are well informed are those who can meaningfully contribute in this mission. In a systematic review [16], knowledge was a significant factor which influenced male partner involvement in PMTCT. It therefore holds that male partners who demonstrate poor knowledge will make insignificant impact in PMTCT programs. This highlights the need to scale-up male education on PMTCT and target sensitization for men by various means [25] [26] [27]. Such sensitization activities may involve the pasting of flyers and posters in strategic places, contracting the media to discuss and promote male participation in HIV/PMTCT [26] and organizing seminars/workshops for men on HIV/PMTCT. This knowledge deficit, and hence a potential barrier observed among the respondents in this study also calls to question the adequacy of sensitization on the part of health workers regarding PMTCT. There is a need to review training of health educators, nurses, and the doctors; who are key players in these PMTCT programs.

Interestingly, however, our study demonstrated an overall good attitudes and involvement in PMTCT activities among the respondents. For instance, no fewer than $61.5 \%$ of respondents: knew that their partners were counselled and tested for HIV in the last pregnancy; discussed counselling with their partner; expressed willingness to discuss counselling in the subsequent pregnancy; had ever accompanied their partner to an MCH/PMTCT clinic; and were ready to accompany their partner to an MCH/PMTCT in the subsequent pregnancy; have been counselled and tested together with their partner at a MCH/PMTCT clinic and devoted interest in participating in the subsequent pregnancy; among others. These observations have great positive implication for the overall goal of the 
program. First, most couples are tested together; testing only the woman could put her in an awkward position, because she risks abandonment and loss of economic support when she tests alone and discloses her status to her husband/partner. Second, non-involvement of male partners makes women to lose a major source of support and encouragement for participation in the program [28]. Male participation is a form of social support for women's participation. This finding however contrast with a few African studies which found married or cohabiting women were less likely to use PMTCT or other HIV services perhaps due to perceived negative reactions from partners [28] [29] [30] [31]. This attitudinal change could be related to the changing roles in the present day society brought about by increased women education and self-reliance.

Regarding sociocultural factors influencing male participation in PMTCT programs, the only factor that is important as indicated by just over half (50.8\%) of the respondents is PMTCT information flow. Participants were in serious disagreement about the opinion that PMTCT information should be given to the men first before the women. This further presents it as a contending issue. In a traditional African society, men assume the role of the head of the family, and are in the forefront of decision-making. It could be reasoned that receiving first-hand information about PMTCT will not only consolidate on the already traditionally established homage enjoyed by men in the family, but will give him sense of control, and hence his maximum cooperation. For example, it was noted that women in PMTCT program talked about instability in their relationships with their husbands and partners and the lack of trust and communication regarding information flow within couples [28]. Such trust issues could in turn make it difficult for men to appreciate the plight of the women, which undermines their participation in the PMTCT program. Among the respondents who took side in this study however, $30.4 \%$ were in disagreement for such opinion. It is therefore advocated that healthcare workers understand the place of integrating male partners in communicating vital information regarding PMTCT, but at the same time, woman's autonomy must be given top priority. Although participants who completed secondary education were more likely to participate in PMTCT services $(\mathrm{p}=0.039)$, this result needs more insight.

Also, this study discovered important programmatic factors that could promote male participation in PMTCT program. About forty percent of the respondents advocated for running PMTCT/Adult ART weekend clinics, and improving health workers' efforts in involving men. Although there were high proportion of the subjects who were undecided regarding these identified factors (38\% and $28.4 \%$ respectively), consideration of these factors could promote male involvement in PMTCT programs. As indicated previously, direct health worker engagement with men enhances increased male participation in maternal and child health services [23]. Restructuring services to accommodate periods suitable for men could play a vital role in persuading male to get involved. The role of health workers in persuading men's uptake of PMTCT services has been documented elsewhere [16]. Hence, health workers who provide information on 
HIV/PMTCT should work beyond promoting male participation to expressly describing men's roles in meeting material needs to support the pregnant partner, monitor ART and infant feeding compliance, and emotional support. Also, running weekend clinic could encourage men who may be engaged during weekdays to participate.

\section{Limitations}

The descriptive survey and the structured data collection instrument used in this study did not enable the participants to express themselves candidly, and thus limited the researchers' ability to probe. If qualitative aspects were included in this study, it could have been more efficient in exploring the respondents' view, deciphering other associated factors and to strengthen the findings of the quantitative study through in-depth interview.

\section{Conclusions}

This study revealed that despite low knowledge of PMTCT among men, there was an overall good level of attitude and involvement among them. It also highlights important sociocultural factors that are worth attention: PMTCT information flow between couples and the role of education in men's involvement in the programs. The study further underscores vital programmatic issues such as running PMTCT/Adult ART weekend clinics, and improving health workers' efforts in involving men in PMTCT, all of which could potentially promote men's active participation. Healthcare workers' identification of these relevant factors and the development of context-specific strategies that limit barriers and facilitate men's participation is therefore paramount in achieving the overall success of the program.

We recommend further research to fully explore the impact of education on men's participation; as well as fully understand the position of men on redesigning PMTCT programs to include running evening clinics, and how it may influence men's active involvement.

\section{Conflicts of Interest}

The authors declare no conflicts of interest regarding the publication of this paper.

\section{References}

[1] Fondoh N.V. and Mom N.A. (2017) Mother-to-Child Transmission of HIV and Its Predictors among HIV-Exposed Infants at the Bamenda Regional Hospital, Cameroon. Africa. African Journal of Laboratory Medicine, 6, a589. https://doi.org/10.4102/ajlm.v6i1.589

[2] Bucagu, M., Bizimana, J.D., Muganda, J. and Humblet, C.P. (2013) Socio-Economic, Clinical and Biological Risk Factors for Mother-to-Child Transmission of HIV-1 in Muhima Health Centre (Rwanda): A Prospective Cohort Study. Archives of Public Health, 71, Article No. 4. http://www.archpublichealth.com/content/71/1/4 
https://doi.org/10.1186/0778-7367-71-4

[3] Blogmaster, L.G. (2014) The Gap Report: The Beginning of the End of the AIDS Epidemic. UNAIDS, Geneva.

[4] Iwelumnor, J., Ezeanolue, E.E., Airhihenbuwa, C.O., Obiefune, M.C., Ezeanolue, C.O. and Ogedegbe, G.G. (2014) Socio-Cultural Factors Influencing the Prevention of Mother-to-Child Transmission of HIV in Nigeria: A Synthesis of the Literature. BMC Public Health, 14, Article No. 771.

http://www.biomedcentral.com/1471-2458/14/771 https://doi.org/10.1186/1471-2458-14-771

[5] National Agency for the Control of AIDS (2012) Nigeria Global AIDS Response, County Progress Report. National Agency for the Control of AIDS, Abuja, Nigeria.

[6] Ezeanolue, E.E., Obiefuna, M.C, Yang, W., Obaro, S.K., Ezeanolue, C.O. and Ogedegbe, G.G. (2013) Comparative Effectiveness of Congregation-Versus Clinic-Based Approach to Prevention of Mother-to-Child HIV Transmission: Study Protocol for a Cluster Randomized Controlled Trial. Implementation Science, 8, Article No. 62. https://doi.org/10.1186/1748-5908-8-62

[7] World Health Organization (2011) Global HIV/AIDS Response. World Health Organization, Geneva.

[8] National Agency for the Control of AIDS (2011) Factsheet 2011, Update on the HIV/AIDS Epidemic and Response in Nigeria. National Agency for the Control of AIDS, Abuja, Nigeria.

[9] UNAIDS (2013) Progress Report on the Global Plan towards the Elimination of New HIV Infections among Children by 2015 and Keeping Their Mothers Alive. UNAIDS, Geneva.

[10] Van Lettow, M., Landes, M., Van Oosterhout, J.J, Schouten, E., Phiri, H. and Nkhoma, E. (2018) Prevention of Mother-to-Child Transmission of HIV: A CrossSectional Study in Malawi. Bull of World Health Organization, 96, 256-265. https://doi.org/10.2471/BLT.17.203265

[11] Huang, Z., Jin, M., Zhou, H., Dong, Z., Zhang, S., Han, J., et al. (2015) The Uptake of Prevention of Mother-to-Child HIV Transmission Programs in China: A Systematic Review and Meta-Analysis. PLoS ONE, 10, e0135068. https://doi.org/10.1371/journal.pone.0135068

[12] Takah, N.F., Kennedy, I.T.R. and Johnman, C. (2016) Impact of Approaches in Improving Male Partner Involvement in the Prevention of Mother-to-Child Transmission (PMTCT) of HIV on the Uptake of PMTCT Services in Sub-Saharan Africa: A Protocol of a Systematic Review and Meta-Analysis. BMJ Open, 6, e012224. https://doi.org/10.1136/bmjopen-2016-012224

[13] Medley, A., Garcia-Moreno, C., McGill, S and Maman, S. (2004) Rates, Barriers and Outcomes of HIV Serostatus Disclosure among Women in Developing Countries: Implication for Prevention of Mother-to-Child Transmission Programmes. Bulletin of the World Health Organization, 82, 299-304.

[14] Bolu, O.O., Allread, V., Creek, T., Stringer, E., Forna, F., Bulterys, M., et al. (2007) Approaches for Scaling up Human Immunodeficiency Virus Testing and Counselling in Prevention of Mother-to-Child Human Immunodeficiency Virus Transmission Settings in Resource-Limited Countries. American Journal of Obstetrics \& Gynecology, 197, S83-S89. https://doi.org/10.1016/j.ajog.2007.03.006

[15] Orne-Gliemann, J., Becquet, R., Ekouevi, D.K., Leroy, V., Perez, F. and Dabis, F. (2008) Children and HIV/AIDS: From Research to Policy and Action in ResourceLimited Settings. AIDS, 22, 797-805. 
https://doi.org/10.1097/QAD.0b013e3282f4f45a

[16] Morfaw, F., Mbuagbaw, L., Thabane, L., Rodrigues, C., Wunderlich, A., Nana, P., et al. (2013) Male Involvement in Prevention Programs of Mother to Child Transmission of HIV: A Systematic Review to Identify Barriers and Facilitators. Systematic Reviews, 2, Article No. 5. http://www.systematicreviewsjournal.com/content/2/1/5 https://doi.org/10.1186/2046-4053-2-5

[17] Betancourt, T.S., Abrams, E.J., McBain, R. and Smith Fawzi, M.C. (2010) Family-Centred Approaches to the Prevention of Mother to Child Transmission of HIV. Journal of the International AIDS Society, 13, S2. https://doi.org/10.1186/1758-2652-13-S2-S2

[18] Peacock, D. and Levack, A. (2004) The Men as Partners Program in South Africa: Reaching Men to End Gender Based Violence and Promote Sexual and Reproductive Health. International Journal of Men's Health, 3, 173-188.

[19] Adam, A., Barbra, R., Rose, B., John-Stewart, G. and Mbori-Ngacha, D. (2011) Male Antenatal Attendance and HIV Testing Are Associated with Decreased Infant HIV Infection and Increased HIV-Free Survival. Journal of Acquired Immune Deficiency Syndromes, 56, 76-82. https://doi.org/10.1097/QAI.0b013e3181fdb4c4

[20] World Health Organization (2012) Male Involvement in the Prevention of Mother-to-Child Transmission of HIV. WHO, Geneva, Switzerland.

[21] Matseke, M.G., Ruiter, R.A.C., Rodriguez, V.J., Peltzer, K., Setswe, G. and Sifunda, S. (2017) Factors Associated with Male Partner Involvement in Programs for the Prevention of Mother-to-Child Transmission of HIV in Rural South Africa. International Journal of Environmental Research and Public Health, 14, 1333. https://doi.org/10.3390/ijerph14111333

[22] Peacock, D., Stemple, L., Sawires, S. and Coates, T. (2009) Men, HIV/AIDS, and Human Rights. Journal of Acquired Immune Deficiency Syndromes, 51, 119-125. https://doi.org/10.1097/QAI.0b013e3181aafd8a

[23] Ladur, A.N, Colvin, C.J. and Stinson, K. (2015) Perceptions of Community Members and Healthcare Workers on Male Involvement in Prevention of Mother-toChild Transmission Services in Khayelitsha, Cape Town, South Africa. PLoS ONE, 10, e0133239. https://doi.org/10.1371/journal.pone.0133239

[24] Aarnio, P., Olsson, P., Chimbiri, A. and Kulmala, T. (2009) Male Involvement in Antenatal HIV Counseling and Testing: Exploring Men's Perception in Rural Malawi. AIDS Care, 21, 1537-1546. https://doi.org/10.1080/09540120902903719

[25] Theuring, S., Mbezi, P., Luvanda, H., Jordan-Harder, B., Kunz, A. and Harms G. (2009) Male Involvement in PMTCT Services in Mbeya Region, Tanzania. AIDS and Behavior, 13, 92-102. https://doi.org/10.1007/s10461-009-9543-0

[26] Mohlala, B.K, Boily, M.C. and Gregson, S. (2011) The Forgotten Half of Equation: Randomized Controlled Trial of Male Invitation to Attend Couple Voluntary Counselling and Testing. AIDS, 25, 1535-1541. https://doi.org/10.1097/QAD.0b013e328348fb85

[27] Nkuoh, N.G., Meyer, D.J., Tih, P.M. and Nkfusai, J. (2010) Barriers to Men's Participation in Antenatal and Prevention of Mother-to-Child HIV Transmission Care in Cameroon, Africa. Journal of Midwifery Women's Health, 55, 363-369. https://doi.org/10.1016/j.jmwh.2010.02.009

[28] Flax, V.L., Yourkavitch, J., Okello, E.S., Kadzandira, J., Katahoire, A.R. and Munthali, A.C. (2017) "If My Husband Leaves Me, I Will Go Home and Suffer, So Better Cling to Him and Hide This Thing": The Influence of Gender on Option B+ Prevention of Mother-to-Child Transmission Participation in Malawi and Uganda. 
PLoS ONE, 12, e0178298. https://doi.org/10.1371/journal.pone.0178298

[29] Wringe, A., Isingo, R., Urassa, M., et al. (2008) Uptake of HIV Voluntary Counselling and Testing Services in Rural Tanzania: Implications for Effective HIV Prevention and Equitable Access to Treatment. Tropical Medicine \& International Health, 13, 319-327. https://doi.org/10.1111/j.1365-3156.2008.02005.x

[30] Ekouevi, D.K., Leroy, V., Viho, A., et al. (2004) Acceptability and Uptake of a Package to Prevent Mother-to-Child Transmission Using Rapid HIV Testing in Abidjan, Côte d'Ivoire. AIDS, 18, 697-700. https://doi.org/10.1097/00002030-200403050-00018

[31] Muchedzi, A., Chandisarewa, W., Keatinge, J., et al. (2010) Factors Associated with Access to HIV Care and Treatment in a Prevention of Mother to Child Transmission Programme in Urban Zimbabwe. Journal of the International AIDS Society, 13, 38. https://doi.org/10.1186/1758-2652-13-38 


\section{Appendix}

\section{QUESTIONNAIRE}

Prevention of Maternal-to-Child Transmission of HIV: Knowledge, Attitude and Factors Influencing Active Participation among HIV-Positive Men in a Military Health Facility in Lagos, South Western Nigeria.

Dear Respondent

This questionnaire is aimed at assessing the knowledge, attitude and practice towards prevention of mother to child transmission of HIV/AIDS among HIV positive male attending clinic at Army hospital in Lagos. You are going to be asked some questions and accepting to answer by checking the box below means you are willing want to participate in the study. Please answer the question as accurately as possible as you can. All information provided will be handled confidentially. Your name is not required.

Agree $\quad[\quad$ Don't Agree [ ] ]
A) SECTION 1: SOCIO - DEMOGRAPHIC CHARACTERISTICS

1) Age in years as at last birthday

2) What is the highest level of school did you complete? (Tick one)

a) Never attended school [ ]

b) Did not complete primary school [ ]

c) Completed primary school [ ]

d) Did not complete secondary school [ ]

e) Completed secondary school [ ]

f) Did not complete college/University [ ]

g) Completed college/University [ ]

3) For how long have you been living with your current wife/partner? (Tick one)
a) Less than 5 years [
b) 5 to 10 years [ ]

c) More than 10 years [ ]

4) What religion do you belong to? (Tick one )
a) Christian [ ]
b) Muslim [ ]
c) pagan [ ]
d) Other religion (Specify)

5) What tribe are you? (Tick one )
a) Igbo [ ]
b) Hausa [ ]
c) Yoruba [ ]
d) Other (specify)

6) Are you currently working?
a) No [ ]
b) Yes [
c) specify

B) SECTION 2: KNOWLEDGE AND AWARENESS OF PMTCT.

7) Have you heard of HIV/AIDS
a) Yes [ ]
b) No [
c) Don't know [ ]

8) If yes to question 7 what was your source of information? (tick all that apply)

a) Friend [ ] b) Relative [ ] c) Hospital [ ] d) School teacher [ ] e) Radio [ ] f) Television [ ] g) Newspaper/Magazine [ ] h) Social gathering [ ] i) Other specify -----

9) Have you ever heard about a programme called Prevention of Mother to 


\section{Child Transmission (PMTCT)?}

Yes No

Don't know

10) Are PMTCT services offered at this Hospital?
Yes
No
Don't know

11) At the PMTCT clinics, are pregnant women counseled and tested for HIV?

Yes

No

Don't know

12) Can a pregnant woman be HIV positive?

Yes [ ] No [ ] Don't know [ ]

13) Can HIV positive husband of a pregnant woman transmit HIV to his wife?

Yes [ ] No[ ] Don't know [ ]

14) a) Can HIV be transmitted from an infected mother to a child?

Yes [ ] No [ ] Don't know [ ]

b) If yes when?

\begin{tabular}{lllll}
\hline & & Yes & No Don't know \\
\hline a & During pregnancy & & \\
b & During labour & & \\
c & During Delivery & & \\
d & During breastfeeding & & \\
\hline
\end{tabular}

15) What do you think will encourage transmission of HIV from mother to child?

\begin{tabular}{|c|c|c|c|c|}
\hline & & Yes & No & Don't know \\
\hline $\mathrm{a}$ & Increased mother's viral load & & & \\
\hline $\mathrm{b}$ & Lack of multivitamins & & & \\
\hline c & When mother is sick & & & \\
\hline $\mathrm{d}$ & Mother having cracked nipples & & & \\
\hline e & Premature baby & & & \\
\hline $\mathrm{f}$ & Hugging the baby & & & \\
\hline g & Sharing same bed with baby & & & \\
\hline
\end{tabular}

16) Mother to child transmission of HIV can be prevented by?

\begin{tabular}{l}
\hline \\
\hline a Pregnant woman eating balance diet \\
b Caesarian section before the onset of labour \\
c Giving of antiretroviral drugs to mother during and after pregnancy \\
d Use of breast milk substitute (powdered milk) \\
e Avoiding breastmilk \\
e Use of directly expressed and boiled mother's breast milk \\
f Breastfeeding baby by another mother who is not HIV infected
\end{tabular}


17) Are you aware that HIV infected pregnant woman should

\begin{tabular}{lll}
\hline & & Yes No Don't know \\
\hline a & Attend Antenatal clinic regularly & \\
b & Be delivered by a skilled attendant (doctor or midwife & \\
c & Visit post-natal clinic 6 weeks after delivery & \\
d & Visit family planning clinic 6 weeks after delivery & \\
\hline
\end{tabular}

\section{C) SECTION 3: LEVEL OF INVOLVEMENT:}

18) Was your wife/partner counseled and tested for HIV the last time she was pregnant?

(Tick one)

Yes

No.

Don't know

19) Did you discussed with your wife/partner about counseling and testing for HIV last time she was pregnant?

Yes

No.

Don't know

20) Will you discuss with your wife/partner about counseling and testing for HIV next time she is a pregnant?

Yes

No.

Don't know

21) Have you ever gone together with your wife/partner to an MCH/PMTCT clinic?

Yes No.

Don't know

22) Will you go together with your wife/partner to an MCH/PMTCT clinic next time she is pregnant?

Yes No.

Don't know

23) Have you been counseled and tested for HIV together with your wife/partner at a MCH/PMTCT clinic?

Yes

No.

Don't know

24) Will you go for counseling and testing for HIV together with your wife, next time she is pregnant?

Yes

No.

Don't know

25) If your wife/partner is found to be HIV positive when she is pregnant, will you accept that she takes ARVs to protect her unborn baby?

Yes

No.

Don't know

26) If your wife/partner is found to be HIV positive when she is pregnant, will you accept that she does not breastfeed to protect her unborn baby?

Yes

No.

Don't know

27) If your wife/partner is advised not to breastfeed, will you buy formula milk for the baby?

D) SECTION 4: SOCIO CULTURAL FACTORS:

Instructions. mark the appropriate number reflecting the respondent opinion as follows: 
Strongly agree (SA), Agree (A), Undecided (U), Disagree (D), Strongly disagree $(S D)$

$\begin{array}{cccccc}28 & \text { SA } & \text { A } & \text { U } & \text { D } & \text { SD } \\ & 1 & 2 & 3 & 4 & 5\end{array}$

a) A pregnant woman can be tested for HIV without the permission of her husband/partner.

b) Men should accompany their pregnant wives/partners to ANC/PMTCT clinics.

c) Men who accompany their female partners to ANC/PMTCT clinics are weak or bewitched.

d) It is a taboo for men to discuss with women about HIV testing during pregnancy.

e) Men and women should undergo HIV testing at the same time at PMTCT clinics.

f) Couples can use condoms to reduce chances of mother to child transmission of HIV.

g) ANC/PMTCT clinics are for women and children only.

h) A positive HIV test in a pregnant woman shows that she has been unfaithful to her husband.

i) If a pregnant woman is found to be HIV positive, she should be divorced.

j) PMTCT information should first be given first to men then to women.

\section{Total score}

\section{E) SECTION 5: PROGRAMMATIC FACTORS:}

Instructions. Circle the appropriate number reflecting the respondent opinion as follows:

Strongly agree (SA), Agree (A), Undecided (U), Disagree (D), Strongly disag$\operatorname{ree}(S D)$

a) Men should have "male only PMTCT clinics".

b) At the PMTCT clinics Men should be attended to by Male health workers only.

c) Health workers do not like to see men at PMTCT clinics

d) MCH/PMTCT clinics are made for women and children only

e) PMTCT/Adult ART clinics should also be opened during weekends and evening so that men can access also

f) Staff at the PMTCT/Adult ART clinic do not keep any secret about HIV results of men and women

g) PMTCT programmes have done very little to involve men

h) You can attend PMTCT clinic if invited by health worker to come 


\section{Continued}

i) PMTCT clinics are conducted very far from your home and transport is expensive

j) You can do HIV test with your wife, only if you are promised to be given $A R V_{S}$ thereafter

Total score 